\title{
Multi-objective decision making for basin water allocation
}

\author{
R. Roozbahani ${ }^{\mathrm{a}}$, S. Schreider ${ }^{\mathrm{a}}$ and B. Abbasi ${ }^{\mathrm{a}}$ \\ ${ }^{a}$ School of Mathematical and Geospatial Sciences, RMIT University, Melbourne, VIC 3001, Australia \\ Email: Reza.Roozbahani@rmit.edu.au
}

\begin{abstract}
Due to the significant role of water use in socio-economic development, competition for a larger share in water allocation is intense among stakeholders in watersheds. In this paper, three optimization models are developed to explore the optimal allocation of water among users, thus to resolve water conflicts in watersheds. The first model is a linear programming model. The objective function of this model maximizes the basins' revenue. The second model is a multi-objective optimization model. The objective functions of this model maximize the marginal value of water for stakeholders when environmental water supply is a constraint in the model. The third model is also a multi-objective programming model. Three objective functions; maximizing a basin revenue, minimizing the environmental water shortages, and minimizing water transfer from upstream area to downstream region are considered. These models are applied to the Sefidrud Basin, a watershed with eight administrative provinces, each considered as a stakeholder for the modelling. The formulations of three water allocation models are presented and the results of their implementation are compared. The results from the third model show that it would be able to supply more water to agriculture than other models if water authorities would not want the full satisfaction of environmental demand. In other words, if environment is taken into account as a stakeholder, for whom water shortages are acceptable, the third model is recommended. The comparison of the first and the second models reveals that the second model allocates water to stakeholders more equitably than the first model. In the case of the second model, the percentage of maximum and minimum water shortages for the Sefidrud Basin's stakeholders are 71 and 20, respectively, in comparison with 81 and 8 provided by the first model. Hence, we recommend using the second model for resolving water conflicts in watersheds when the satisfaction of environmental water requirements is crucial for water authorities. The policy of water authorities on environmental water satisfaction is a key factor determining the water allocation pattern of the Basin. Therefore, the issue of whether any shortages in environmental water supply are tolerable should be resolved before any decision related to water allocation is made.
\end{abstract}

Keywords: Water allocation, linear programming, multi-objective programming, conflict resolution 


\section{INTRODUCTION}

Water is a limited natural resource that is necessary for any socio-economic development. Due to rapid increase in water demand associated with rapid population growth, water scarcity is now a big issue all around the world. The inaccessibility of adequate water in watersheds causes strong competition between their stakeholders. Therefore, water allocation is receiving considerable attention among water researchers nowadays.

Numerous mathematical models have been developed to address water allocation issues in different watersheds. These models can be classified into two main categories; the single objective and the multi objectives models. The studies of Roozbahani et al. (2013), Pulido-Velázquez et al. (2006), and Dinar et al. (2008), in which the authors used linear programming, nonlinear programming, and game theory techniques respectively, are categorised as single objective methods where only one water allocation indicator is taken into consideration for resolving water conflicts in watersheds. In the same way, multi-criteria decision making (Straton et al., 2011) and multi-objective decision making (Yang et al., 2013) are considered as multi objective models where they determine the share of each stakeholder from watershed's water resources using more than one water allocation indicator.

This paper aims to introduce three water allocation models based on linear programming (single objective algorithm methods) and multi-objective optimization for resolving water conflicts in watersheds and compare their capability by implementing them for conflict resolution in a real water dispute. The first model is a linear programming model, in which maximizing watersheds revenue is its objective function. The second model is a multi-objective model that allocates water between a basin's stakeholders by maximizing the revenue of each stakeholder. The third model is also a multi-objective model with three objective functions but it does not directly involve stakeholders to allocate basins' water resources between them. The main difference of the first and the second models with the third one is that water supply to environment is considered to be a constraint in the first and the second models whereas it is an objective function in the third model.

The aforementioned models are applied to the Sefidrud Basin, northern Iran where water conflicts between its stakeholders are quite intensive. The high water demands of stakeholders (eight provinces), which are mainly for socio-economic development, create these water disputes. In this paper, the results of models, in terms of the way they determine the water share of each stakeholder from the Basin's water resources, are presented and compared.

\section{WATER ALLOCATION MODELS}

This section briefly describes the formulation of three water allocation models which are based on a network structure (nodes and arcs). In regard to the large amount of water used in agricultural sector compared with domestic and industrial sectors, agriculture is considered to be the main user of water in a watershed for all models, and other demands are neglected.

\subsection{First Model: Linear Programming Model}

The first model is a single objective model that maximises the income of a basin from allocated water to agriculture. The objective function of this model is expressed as:

Maximize $Z=\sum_{t} \sum_{i=1}^{\mathrm{n}}\left(\mathrm{p}_{i_{k}} \times\left(x_{t i_{k}}^{s}+x_{t i_{k}}^{g}\right)\right)$

subject to:

$$
\begin{aligned}
& \mathrm{SW}_{t i_{k}}+\sum_{l \in U N} x_{t l_{k} i}^{t}-x_{t i_{k} j}^{t}-x_{t i_{k}}^{s}=0 \\
& x_{t i_{k} j}^{t}-\mathrm{ED}_{t i_{k}} \times x_{t i_{k}}^{\varepsilon} \geq 0 \\
& \sum_{t} x_{t i_{k}}^{\varepsilon}-\mathrm{R} \geq 0 \\
& \mathrm{FA}_{i_{k}} \times \mathrm{WN}_{t i_{k}}-x_{t i_{k}}^{s}-x_{t i_{k}}^{g} \geq 0 \\
& \mathrm{GW}_{t i_{k}}-x_{t i_{k}}^{g} \geq 0
\end{aligned}
$$

where:

$n$ number of nodes;

$$
\begin{aligned}
& x_{t i_{k}}^{S} \geq 0 \\
& x_{t i_{k}}^{g} \geq 0 \\
& x_{t i_{k} j}^{t} \geq 0 \\
& x_{t i_{k}}^{\varepsilon}=0 \text { or } 1
\end{aligned}
$$

$k$ index for indication stakeholders; 
$i$ node;

$t$ time step;

$\mathrm{p}_{i_{k}}$ water profit of agricultural sector in node $i$ in stakeholder $k$;

$x_{t i_{k} j}^{t}$ transferred surface water from supply node $i$ for stakeholder $k$ to supply node $j$ in time step $t$;

$x_{t i_{k}}^{S}$ surface water supply to agriculture in node $i$ in time step $t$;

$x_{t i_{k}}^{g}$ groundwater supply to agriculture in node $i$ in stakeholder $k$ in time step $t$.

$\mathrm{SW}_{t i_{k}}$ produced surface water in the catchment of node $i$ in stakeholder $k$ in time step $t$;

Equation (2) represents the water balance in node $i$. Water inputs to node $i$ are the produced surface water in its catchment and the water from nodes $l(l \in \mathrm{UN}$ where $\mathrm{UN}$ is the set of upstream neighbouring nodes of node $i$ ) to $i$. Water released from node $i$ is water supplied for demand in node $i$ and water released to downstream. The satisfaction of environmental water requirements is considered to be the sustainability criterion for water planning in the model. For this purpose, the amount of transferred water from node $i$ to node $j$ in time step $t$ has to be greater or equal to the environmental water requirement in node $i$ (constraint (3)). To control the reliability of the environmental water supply, a binary variable $\left(x_{t i_{k}}^{\varepsilon}\right)$ is considered in constraint (3) which is 1 if the environmental water requirement is satisfied. The sum of this binary variable over the time steps has to be more than or equal to $\mathrm{R}$, the reliability level of the environmental water supply (constraint (4)). The amount of water supplied to agriculture should not exceed agricultural water need in each node. This limitation is considered in the model using inequality (5). Furthermore, the water supplied from the groundwater resources in each node has to be less than or equal to its available groundwater (constraint (6)). Finally, the decision variables of the model obviously must be non-negative (constraints (7)-(10)).

\subsection{Second Model: Multi-objective Model (Maximizing the Income of each Stakeholder)}

The unequal development and consequently unfair income generation between stakeholders is the main reason for water disputes in a watershed. Thus, maximization of the income of each stakeholder is considered as an indicator for water allocation in the second model. The formulation of the second model is as follows:

Maximise $Z_{k}=\sum_{t} \sum_{i_{k}=1}^{n}\left(\mathrm{p}_{i_{k}} \times\left(x_{t i_{k}}^{s}+x_{t i_{k}}^{g}\right)\right)$

Subject to:

constraints (2)-(10).

A new method is proposed to find a fair solution for the second model. This method is based on allocating water to stakeholders in a way that the revenues of stakeholders are the maximum percentage of their highest possible profit, when this percentage is the same for all stakeholders. This ratio (percentage) can be achieved by the following formulation:

Maximise $\left\{Z_{t}=\lambda_{t}\right\}$

Subject to:

$\sum_{i_{k}=1}^{n}\left(\mathrm{p}_{i_{k}} \times\left(x_{t i_{k}}^{s}+x_{t i_{k}}^{g}\right)\right) \geq\left(\lambda_{t} \times \mathrm{f}_{t k}^{*}\right)$

and constraints (2) to (10).

where:

$\lambda_{t}$ ratio of stakeholder's income to the maximum possible profit of stakeholder for each time step $t$;

$\mathrm{f}_{t k}^{*}$ maximum possible income of stakeholder $k$ in time step $t$.

The objective function is subject to the income of each province in time step $t$ which has to be greater than or equal $\lambda$ times to maximum possible income of province $k$ in time step $t$. Further description of the solution method is given in (Roozbahani et al., submitted). 


\subsection{Third Model: Multi-objective Model (with Three Objective Functions)}

The third model has three objective functions. Maximizing a basin income from agricultural sectors is the first objective function of the model. For evaluating the effect of water supply to the environment on the water allocation pattern, constraints (3) and (4) are not considered in this model, and instead minimizing the environmental water shortage is taken into consideration as the second objective function. In general, the main part of the basin's surface water resources is harvested in upstream areas. Therefore, there is a high public expectation for using surface water resources generated in upstream areas, instead of releasing it downstream. The third objective function minimizes the volume of surface water transferred to the downstream regions, which is an indicator quantifying the social justice in the Basin. The formulation of the third model is:

$$
\begin{aligned}
& \text { Maximize } Z_{1}=\sum_{t} \sum_{i=1}^{\mathrm{n}}\left(\mathrm{p}_{i_{k}} \times\left(x_{t i_{k}}^{S}+x_{t i_{k}}^{g}\right)\right) \\
& \text { Minimize } Z_{2}=\sum_{t} \sum_{i=1}^{\mathrm{n}} x_{t i_{k}}^{\delta} \\
& \text { Minimize } Z_{3}=\sum_{t} \sum_{i=1}^{\mathrm{n}} x_{t i_{k} j}^{t}
\end{aligned}
$$

subject to:

$x_{t i_{k} j}^{t}+x_{t i_{k}}^{\delta}-\mathrm{ED}_{t i_{k}} \geq 0$ for all $t, i$, and $k$

and constraints (2) and (5)-(9).

where $x_{t i_{k}}^{\delta}$ is the environmental water shortage in node $i$ in stakeholder $k$ in time step $t$. Compromise programming (Zeleny, 1973) was employed to find optimal solutions for the third model. Compromise programming distance metric can be presented in generic form as follows:

Minimize $L=\left[\sum_{i=1}^{r} w_{i}^{p}\left(\frac{z_{i}^{*}-Z_{i}(x)}{Z_{i}^{*}-Z_{i}^{* *}}\right)^{p}\right]^{1 / p}$

where

$i 1,2,3 \ldots r . r$ is the number of objectives;

$L$ distance metric to ideal point;

$p$ is a parameter of this metric and can be equal to

1,2 , and $\infty$;

$w_{i}$ corresponds to a weight of a particular

objective;

It is considered that the values $w_{\mathrm{i}}$ (the weight of objective $i$ ) reflect the preference of decision makers regarding the importance of criteria. Also, the parameter $p$ reveals the importance of the maximal deviation from the ideal point. The value of $p=1$ represents the situation where all deviations have equal weights. For $p=2$ each deviation gives weight according to its magnitude and increases with $p$. The largest deviation from the ideal point is considered when $p=\infty$. Varying the parameter $p$ from 1 to infinity allows researchers to move from minimizing the sum of individual regrets to minimizing the maximum regret in the decisionmaking process.

\section{THE SEFIDRUD BASIN}

The Sefidrud Basin, in northern Iran, is the case study area for this study, where there is conflict between its stakeholders over water allocation. The basin area is $59217 \mathrm{~km}^{2}$ (MGC, 2011), and eight provinces, namely, Kordestan (Province 1), Hamedan (Province 2), Zanjan (Province 3), East Azarbaijan (Province 4), Ardabil (Province 5), Tehran (Province 6), Qazvin (Province 7) and Gilan (Province 8) are its stakeholders. The main rivers of the Basin, the Ghezelozan and the Shahrud rivers, flow from south to north and east to west respectively. They join together in the Gilan province, and with the name of the Sefidrud River, discharges into the Caspian Sea (Figure 1). The watershed's total water yield is 7615 million cubic meters (MCM), which is $6214 \mathrm{MCM}$ surface water and $1337 \mathrm{MCM}$ groundwater (MGC, 2011). Agriculture is the main user of water in this Basin and the water requirements of domestic and industry sectors are not significant. The annual agricultural water demand for 2025 is estimated to be $7270 \mathrm{MCM}$. The future basin agricultural demands, as well as the irrigated agriculture incomes for each province, are shown in Table 1 (MGC, 2011). The reader is referred to Roozbahani et al. (2013a) for more details about the Basin's water resources and demand.

The stylized network representation of the Basin is shown in Figure 2. It includes 27 supply/demand nodes scattered among provinces. These nodes are associated with the stream flow gauges in the basin and they 
provide surface water for agricultural use in their vicinities. Each agricultural demand site is supplied from the two separate sources of surface and groundwater. When more than one node is situated in a province, the sum of the water allocated from these nodes represents the total amount of water allocated to the relevant province. For the water allocation purpose, when a node belongs to more than one province, the allocated water to the node is shared between the provinces based on the province demand to the node demand ratio.

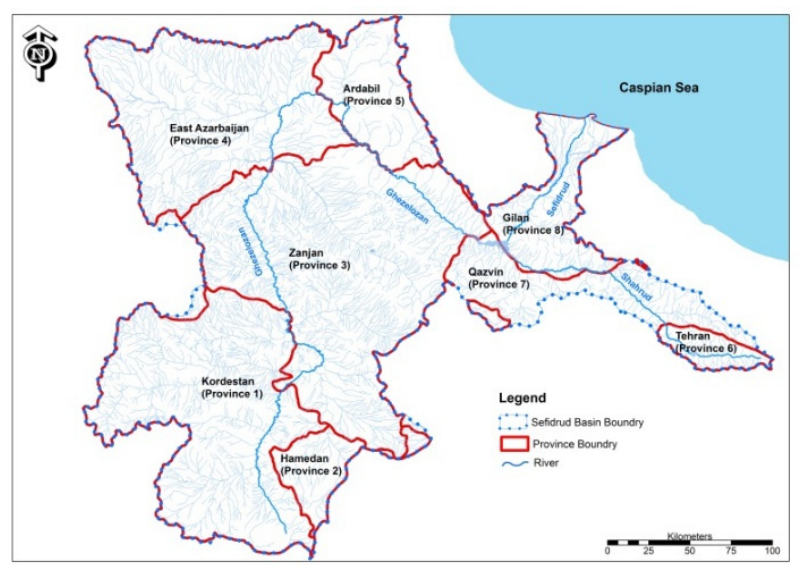

Figure 1. The Sefidrud Basin and its stakeholders

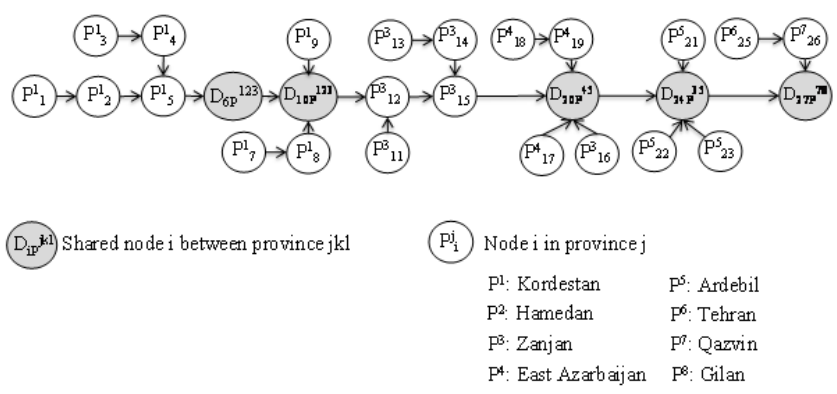

Figure 2. The Sefidrud Basin network

\section{RESULTS AND DISCUSSIONS}

In this section, the results of models are presented and compared. Here, it should be explained that the $90 \%$ threshold of demand satisfaction in $90 \%$ of time steps is to be a major reliability criterion for water supply systems in Iran (Torabi-Palatkaleh et al., 2010). Therefore, the value of the parameter R (reliability threshold for environmental water supply) in the first and second models is 540 (The number 540 is the product of the number of time steps (600) times and the threshold of demand satisfaction (90\%)). In addition, the modified version of the Montana method proposed by Torabi-Palatkaleh et al. (2009) is used to estimate the environmental water demands in the Basin nodes.

Given that the compromise programming is used to find the values of decision variables for the third model, the model's objective functions can have different weights, and the model is capable of producing different water allocation patterns related to various set of weights. In this paper, the results of the third model with the set of weights $w_{1}=0.1, w_{2}=0.8$, and $w_{3}=0.1\left(w_{1}, w_{2}\right.$, and $w_{3}$ are the weights of the first, the second, and the third objective function respectively), are presented. In this set, the weight of the second objective function (minimizing the environmental water shortage) is 0.8 . It means that water supply to environment has a high priority over other objective functions. In this case, the third model would have the closest behavior to the first and the second models where they are constrained to supply environmental water need in $90 \%$ of time steps and as a result, the comparison of their results is reasonable.

\subsection{Comparison}

Figure 3 presents total amounts of water which were allocated to agriculture by the models. As shown in this figure, the total water supply to agriculture by the third model is $5380 \mathrm{MCM}$ whereas it is 4489 and 4328 MCM for the first and the second models, respectively. The main reason for these differences; 891 MCM between the third and the first models and $1052 \mathrm{MCM}$ between the third and the second models; is that water 
supply to the environment was considered to be a severe constraint in the first and the second models, and it had to be satisfied with high reliability. Therefore, they have to supply the environmental water requirements of nodes in $90 \%$ of time steps. However, water supply to the environment is considered to be an objective function in the third model and, with regard to the weight of this objective function and other objective functions, the third model can neglect to satisfy environmental water needs in nodes.

Figure 4 shows the volumetric reliability of environmental water supply for the Basin's nodes when the third model is applied to the Basin. According to this figure, the environmental water requirements of 13 nodes out of 27 nodes are not satisfied by this model. In other words, the model preferred to allocate water to agriculture instead of the environment, although the weight of the second objective function (minimizing the environmental water shortage) is higher than other objective functions. It seems that the proposed water allocation pattern by the third model does not match up with the sustainable water allocation pattern for the Basin which in the sustainable pattern, the environmental water requirement of all nodes has to be satisfied at least with $90 \%$ of volumetric reliability (Torabi-Palatkaleh et al., 2010).

For comparing the first and the second models, the agricultural water deficits of stakeholders given by the first and the second models were evaluated (Figure 5). As presented in this figure, the second model distributes the shortages of water between the Basin's stakeholders more equitably. The maximum and minimum of water shortages given by the first model are $81 \%$ (for stakeholder 6 ) and $8 \%$ (for stakeholder 8 ), whereas these percentages for the second model are $71 \%$ (for stakeholder 6) and $20 \%$ (for stakeholder 7 ). In addition, the absolute difference of water shortages (in percent) in each pair of nodes is calculated for the first and second models, for instance paired nodes 1 and 2, nodes 1 and 3 , nodes 1 and $4, \ldots$, and finally nodes 7 and 8. The summation of these differences is considered to be another criterion for comparing the first and the second models. These sums are 704 and 525 for the first and the second models, respectively. According to these values, the Basin's water resources are allocated more equitably between the Basin's stakeholders by the second model. It should be mentioned here that the total water allocated to agriculture by the first and the second models (Figure 3) are about equal.

Table 1. The future basin agricultural demand

\begin{tabular}{c|c|c}
\hline Province & $\begin{array}{c}\text { Future Demand } \\
(\mathrm{MCM})\end{array}$ & $\begin{array}{c}\text { Agricultural Water Profit } \\
(\text { Rials/M }\end{array}$ \\
\hline 1 & 1029 & 440 \\
\hline 2 & 126 & 440 \\
\hline 3 & 1967 & 1515 \\
\hline 4 & 753 & 1836 \\
\hline 5 & 447 & 1836 \\
\hline 6 & 410 & 1417 \\
\hline 7 & 431 & 1933 \\
\hline 8 & 2107 & - \\
\hline Sum & 7270 & \\
\hline
\end{tabular}

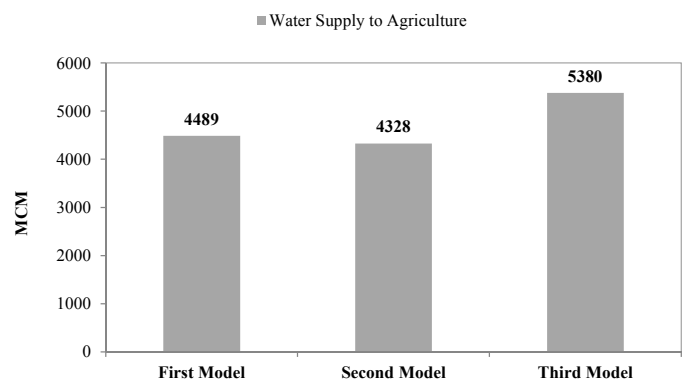

Figure 3. Total allocated water to agriculture in the Basin by models

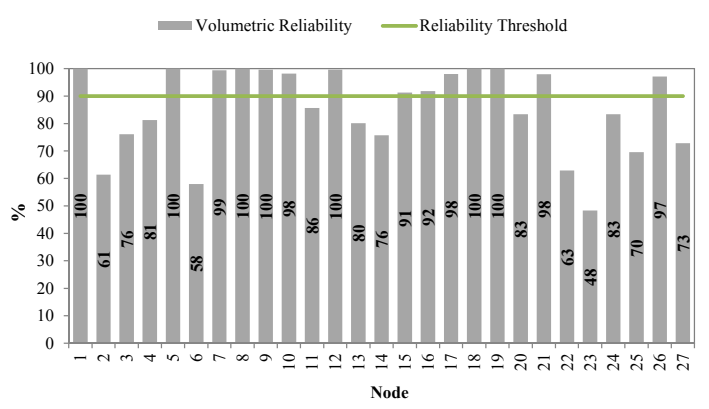

Figure 4. Volumetric reliability of the environmental water supply in the Basin nodes; applying the third model to the Basin (Low percentage of reliability means high environmental water shortage in a node)

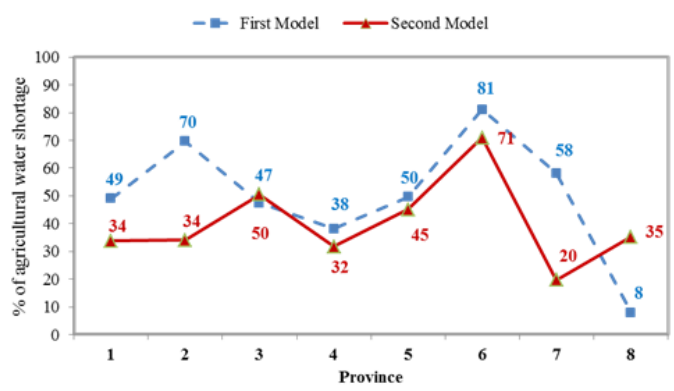

Figure 5. Stakeholders' agricultural water deficits 


\section{CONCLUSIONS}

In this paper, the formulations of three water allocation models were presented and their implementation results were compared. The third model supplies more water to agriculture $(5380 \mathrm{MCM})$ than the other models (4489 MCM and $4328 \mathrm{MCM}$ for the first and the second models respectively) if water authorities did not dictate a $90 \%$ threshold for water supply to the environment as a necessary criterion for a basin's water resources development. In other words, if the environment is taken into account as another stakeholder for which water shortages are acceptable, like other basin's stakeholders (i.e. provinces); the third model is recommended for resolving water conflicts in basins. Furthermore, the third model has this capability that water authorities can consider different weights to objective functions depending on their priority goals and compare different water allocation patterns for basins according to their weights.

The comparison of the first and the second models revealed that the second model allocated water to stakeholders more equitably than the first model, where the percentage of maximum and minimum water shortages for the Sefidrud Basin's stakeholders were given by the second model as 71 and 20 in comparison with 81 and 8 . Therefore, the authors recommend using the second model for resolving water conflicts in watersheds when the satisfaction of environmental water requirements is critically important for the Basin's water authorities.

This paper illustrates how important the environmental demand is and how different policies about satisfying environmental demand influence the water allocation patterns of the Basin. Therefore, the question of whether any shortages in the environmental water supply are tolerable should be answered prior to making any water allocation decision.

\section{REFERENCES}

Dinar, A., Farolfi, S., Patrone, F., and Rowntree, K. (2008). To negotiate or to game theorize: evaluating water allocation mechanisms in the Kat Basin, South Africa. Game Theory and Policy Making in Natural Resources and the Environment, Routledge.

MGC (Mahab Ghods Company). (2011). National water master plan study: The Sefidrud Basin (Technical Report). Tehran, Iranian Ministry of Energy.

Pulido-Velázquez, M., Andreu, J., and Sahuquillo, A. (2006). Economic optimization of conjunctive use of surface water and groundwater at the basin scale. Journal of Water Resources Planning and Management, 132(6), 454-467.

Roozbahani, R., Schreider, S., and Abbasi, B. (2013). Economic sharing of basin water resources between competing stakeholders. Water Resources Management, 27(8), 2965-2988.

Roozbahani, R., Abbasi, B., and Schreider, S. (submitted paper). A multi-objective approach for transboundary river water allocation. European Journal of Operational Research.

Straton, A., Jackson, S., Marinoni, O., Proctor, W., and Woodward, E. (2011). Exploring and evaluating scenarios for a river catchment in northern Australia using scenario development, multi-criteria analysis and a deliberative process as a tool for water planning. Water Resources Management, 25(1), 141-164.

Torabi-Palatkaleh, S., Estiri, K., and Hafez, B. (2009). The role of environmental requirements in process of water allocation for watersheds in Iran: sustainable development approach. 2nd international conference Water, ecosystems and sustainable development in arid and semi-arid zones, Tehran, Iran, 6-8 May, 2009.

Torabi-Palatkaleh, S., Roozbahani, R., Hobevatan, M., and Estiri, K. (2010). Water allocation regulation. Tehran, Iranian Ministry of Energy.

Yang, W., and Yang, Z. (2013). Development of a long-term, ecologically oriented dam release plan for the Lake Baiyangdian Sub-basin, Northern China. Water Resources Management, 27(2), 485-506.

Zeleny, M. (1973). Compromise programming, multiple criteria decision-making. Multiple Criteria Decision Making. J. L. Cochrane and M. Zeleny. Columbia, University of South Carolina Press: 263-301. 